\title{
A Small Increment of External K Concentration Accelerates Adrenomedullary Catecholamine Secretion Induced by Ouabain and Metabolic Inhibitors
}

\author{
Masaru SorimachI and Shigeto NishimURA \\ Department of Physiology, Kagoshima University, School of Medicine, \\ Kagoshima, Kagoshima, 890 Japan
}

\begin{abstract}
Summary In the cat adrenal perfused with a medium containing ouabain, raising the external concentration of $\mathrm{K}$ to $10 \mathrm{~mm}$ abruptly increased the rate of catecholamine secretion. Increased response to $10 \mathrm{mM} \mathrm{K}$ were also observed in the adrenals treated with monoiodoacetate or cyanide, which was suggested to reduce the $\mathrm{Na}$ pumping activity indirectly. Since both the onset time and the magnitude of K-induced secretion are dependent on the concentration of external $\mathrm{Na}$, it was suggested that a small increase of $\mathrm{K}$ concentration accelerates $\mathrm{Ca}$ influx in exchange for internal $\mathrm{Na}$.
\end{abstract}

Key Words: adrenal medulla, catecholamine, ouabain.

Available evidence suggests that the adrenal chromaffin cells possess a $\mathrm{Na}-\mathrm{Ca}$ exchange system similar to that described in the squid axon and cardiac muscle (see review by BAKER and ReUTER, 1975). The rate of ${ }^{45} \mathrm{Ca}$ efflux from the medullary slices (RINK, 1977) and the perfused cortex-free medulla (AGUIRRE et al., 1977) was largely dependent on external $\mathrm{Na}$. Conversely, all the procedures leading to a rise in the concentration of internal $\mathrm{Na}$ was found to increase $\mathrm{Ca}$ influx in exchange for internal $\mathrm{Na}$ (that is, $\mathrm{Na}$-dependent $\mathrm{Ca}$ influx) thereby increasing catecholamine (CA) secretion (ESQUERRO et al., 1980; GARCIA et al., 1980, 1981b; Nishimura et al., 1981; SorimaCHI et al., 1981; SorimaCHI and YAMAGAMI, 1983). Recently, GARCIA et al. (1981a) reported that ouabain treatment of the adrenal gland enabled a small increment of external $\mathrm{K}$ to increase markedly the rate of CA secretion. Since this response persists in the presence of a low concentration of external $\mathrm{Na}(25 \mathrm{~mm})$, a condition abolishing CA secretion due to $\mathrm{Na}$-dependent $\mathrm{Ca}$ influx mechanism, they concluded that another component of the ouabain's effect was involved in this secretion. However, in contrast to their conclusion, we now present evidence showing that a small increase in

Received for publication January 29, 1983

反町 勝, 西村茂人 
external $\mathrm{K}$ concentration somehow increases $\mathrm{CA}$ secretion due to $\mathrm{Na}$-dependent $\mathrm{Ca}$ influx.

Adrenal glands of the cats were retrogradely perfused at room temperature $\left(25-30^{\circ} \mathrm{C}\right)$ with modified Locke's medium containing $\mathrm{NaCl}(150 \mathrm{mM}), \mathrm{KCl}(5 \mathrm{~mm})$ $\mathrm{CaCl}_{2}(2 \mathrm{~mm}), \mathrm{MgCl}_{2}(1 \mathrm{~mm})$, Tris/Cl(5 mM, pH 7.0-7.3), and glucose (5.5 mm) (Douglas and Rubin, 1961). Effluents were collected in test tubes containing appropriate amounts of acetic acid, so that final $\mathrm{pH}$ becomes about 4. Total CA was determined by the conventional fluorimetric method (ANTON and SAYRE, 1962).

Exposure of the adrenal to a medium containing ouabain $(50 \mu \mathrm{M})$ caused a time-dependent increase of CA secretion. During this period, raising external $\mathrm{K}$ from 5 to $10 \mathrm{~mm}$ caused an abrupt increase of secretion rate and this rate immediately diminished following reduction of the concentration of $\mathrm{K}$ to $5 \mathrm{~mm}$. These results are essentially similar to those observed by GARCIA et al. (1981a). However, in sharp contrast to their findings, we have found that the potentiating effect of $10 \mathrm{~mm} \mathrm{~K}$ was dependent on the concentration of $\mathrm{Na}$ in the medium containing ouabain when $\mathrm{Na}$ was partially replaced by Tris. As shown in Fig. 1, a $5 \mathrm{~min}$ exposure to $10 \mathrm{~mm} \mathrm{~K}$ increased secretion rate time-dependently during perfusion with a medium containing $50 \mathrm{~mm} \mathrm{Na}$ (107 mM Tris) only in the presence of ouabain. When the concentration of $\mathrm{Na}$ was reduced to $20 \mathrm{~mm}$ (138 mM Tris), the significant increase of secretion rate in response to $10 \mathrm{~mm} \mathrm{~K}$ was observed only 45-70 min after introduction of ouabain depending on the experiments $(N=4)$. Thereafter, the magnitude of the response to $10 \mathrm{mM} \mathrm{K}$ gradually increased; for example, a seventh exposure to $10 \mathrm{~mm} \mathrm{~K}$ at $15 \mathrm{~min}$ intervals released 2.9 and $8.0 \mu \mathrm{g}$ CA during a $5 \mathrm{~min}$ period above the prestimulation level in two experiments.

On the other hand, when a low Na medium $(25 \mathrm{~mm})$ was prepared by substituting $\mathrm{Na}$ by choline instead of Tris, the substantial increase of secretion rate was observed in response to $10 \mathrm{~mm} \mathrm{~K}$ introduced at the 15 th-20th min period, confirming the results by GARCIA et al. (1981a). However, of importance are our two findings that this response does not require the presence of ouabain, and that cholinergic antagonists ( $1.8 \mathrm{~mm}$ hexamethonium and $0.1 \mathrm{~mm}$ atropine) completely abolish this secretion. The recent finding of choline as a partial nicotinic agonist at the adrenal medulla (Holz and Senter, 1981; SorimaCHI and NiSHIMUrA, 1982) raises the possibility that secretory effect of $10 \mathrm{mM} \mathrm{K}$ in the presence of choline is somehow related to the activation of acetylcholine ( $\mathrm{ACh}$ ) receptors. Indeed, $10 \mathrm{~mm} \mathrm{~K}$ increased the rate of secretion significantly during continuous exposure to a medium containing $\mathrm{ACh}(50 \mu \mathrm{M})$ or pilocarpine $(1 \mathrm{~mm})$, a muscarinic agonist, unless cholinergic antagonists were present. The exact mechanism of K-induced secretion in the presence of $\mathrm{ACh}$ or pilocarpine was not explored in the present study, but these results demonstrate that the observation by GARCIA et al. (1981a) could not be an indication against the involvement of $\mathrm{Na}$-dependent $\mathrm{Ca}$ influx mechanism in the $\mathrm{K}$ secretory response. In a medium containing $25 \mathrm{mM} \mathrm{Na}$ 


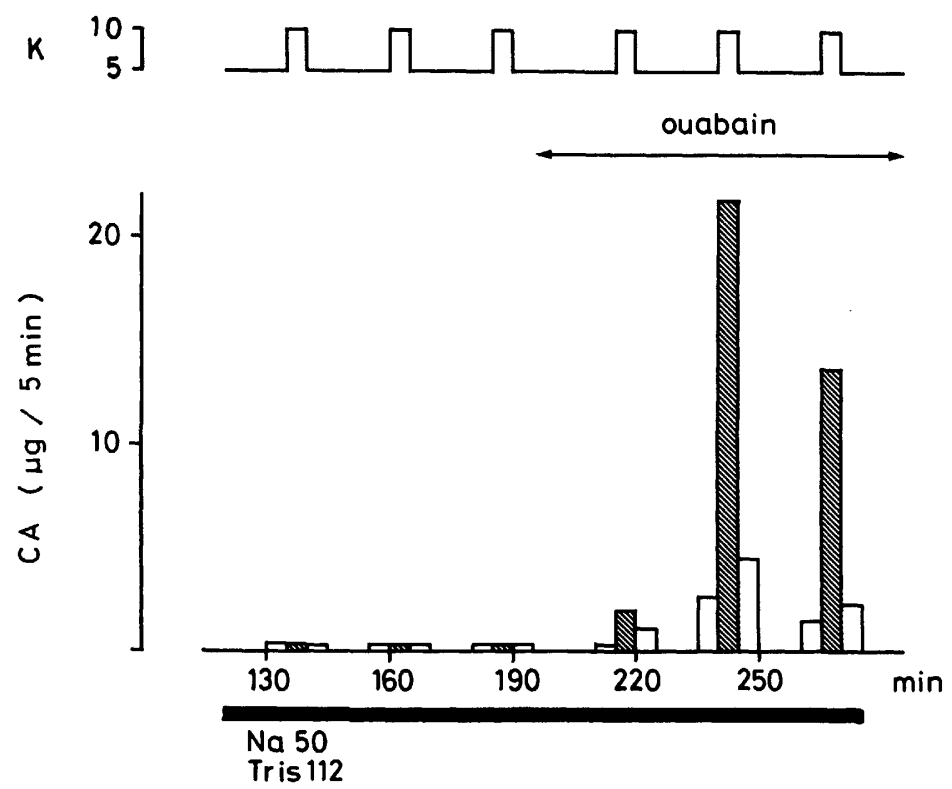

Fig. 1. Effect of raising external $\mathrm{K}$ concentration to $10 \mathrm{~mm}$ for $5 \mathrm{~min}$ during perfusion with a medium containing $50 \mathrm{~mm} \mathrm{Na}(107 \mathrm{~mm}$ Tris) in the presence and absence of ouabain $(50 \mu \mathrm{M})$. Note that no secretory response to $10 \mathrm{~mm} \mathrm{~K}$ was observed in the absence of ouabain. Essentially similar results were obtained in the other four experiments.

(replaced by choline) and cholinergic antagonists, $10 \mathrm{~mm} \mathrm{~K}$ induced a significant increase of secretion only after a long treatment period with ouabain, as was shown in Tris-substituted medium. Thus, in the light of the Na dependency of ouabain's effect on K-induced secretion, it seems reasonable to consider that $\mathrm{Na}$ dependent $\mathrm{Ca}$ influx is accelerated by increasing $\mathrm{K}$ concentration.

To test this possibility further, we have investigated the effect of $10 \mathrm{~mm} \mathrm{~K}$ on CA secretion observed during exposure to a medium containing a metabolic inhibitor, since inhibition of either glycolysis or oxidative phosphorylation was previously suggested to activate this $\mathrm{Ca}$ influx mechanism indirectly via the inhibition of Na pumping (Sorimachi and Yamagami, 1983). As shown in Fig. 2, CA secretion gradually increased during exposure to a medium containing cyanide $(0.2 \mathrm{mM})$ or monoiodoacetate (MIA, $0.2 \mathrm{~mm}$ ), as was observed in the case of ouabain. Raising the concentration of $\mathrm{K}$ to $10 \mathrm{~mm}$ for $5 \mathrm{~min}$ during this period further increased the rate of secretion and this rate diminished in the presence of $5 \mathrm{~mm} \mathrm{~K}$. The stimulatory effect of K lasted even after removal of MIA, but not of cyanide, a finding which is consistent with the different reversibility of the effects of these agents on Na-dependent $\mathrm{Ca}$ influx mechanism (SorimaCHI and YAMAGAMI, 1983).

The rate of CA secretion during perfusion with a medium containing $50 \mathrm{~mm}$ $\mathrm{Na}$ (replaced by Tris) and ouabain was also increased by the addition of $\mathrm{Rb}(5 \mathrm{~mm})$, 


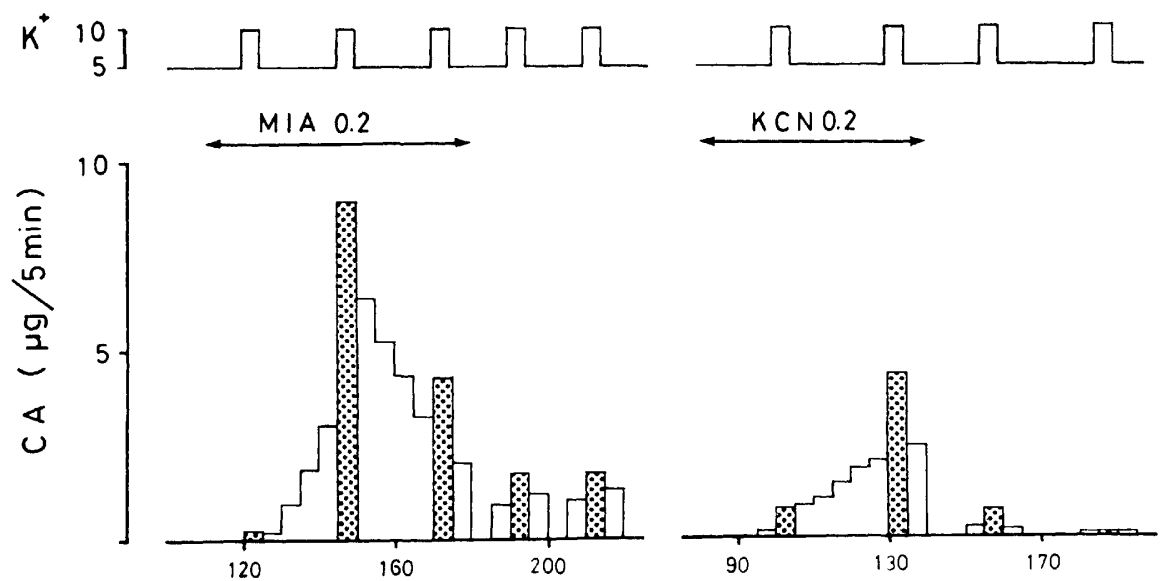

Fig. 2. Effect of raising external $\mathrm{K}$ concentration to $10 \mathrm{mM}$ during perfusion with modified Locke's medium containing monoiodoacetate (MIA, $0.2 \mathrm{mM})$ and $\mathrm{KCN}(0.2 \mathrm{~mm})$. The second pulse of $10 \mathrm{~mm} \mathrm{~K}$ was still effective in increasing secretion after removal of MIA, while that failed to increase secretion after removal of KCN. Similar results were obtained in the other three experiments in each case.

but not of Cs $(5 \mathrm{~mm})$. The secretory effect of a higher concentration of Cs was weakest among alkali metal ions, and this was considered to be due to its weakest depolarizing effect (SoRImaCHI, 1968). If this is feasible, then the result suggests that reduction in the electrochemical gradient for $\mathrm{Na}$ during depolarization by $\mathrm{K}(10 \mathrm{~mm})$ or $\mathrm{K}(5 \mathrm{~mm})$ plus $\mathrm{Rb}(5 \mathrm{~mm})$ diminishes the external $\mathrm{Na}$-dependent $\mathrm{Ca}$ efflux thereby resulting in an increase of Na-dependent $\mathrm{Ca}$ influx, as described in squid axon and cardiac muscle (BAKER and REUTER, 1975). Alternative explanation would be that $\mathrm{Ca}$ channel is somehow modified by an increase of $\mathrm{K}$ or $\mathrm{Rb}$ so that $\mathrm{Ca}$ influx is further increased, since internal $\mathrm{Na}$-dependent $\mathrm{Ca}$ influx is inhibited by Ca channel blockers (Nishimura et al., 1981; Sorimachi and YAMAGAMI, 1983).

\section{REFERENCES}

Aguirre, J., Pinto, J. E. B., and Trifaro, J. M. (1977) Calcium movements during the release of catecholamines from the adrenal medulla: Effects of methoxyverapamil and external cations. J. Physiol. (Lond.), 269: 371-394.

Anton, A. H. and SAYre, D. F. (1962) A study of the factors affecting the aluminum oxidetrihydroxyindole procedure for the analysis of catecholamines. J. Pharmacol. Exp. Ther., 138: $360-375$.

Baker, P. F. and Reuter, H. (1975) Calcium Movements in Excitable Cells, Pergamon Press, $101 \mathrm{pp}$.

Douglas, W. W. and Rubin, R. P. (1961) The role of calcium in the secretory response of the adrenal medulla to acetylcholine. J. Physiol. (Lond.), 159: 40-57.

Esquerro, E., Garcia, A. G., Hernandez, M., Kirpekar, S. M., and Prat, J. C. (1980) Cate- 
cholamine secretory response to calcium reintroduction in the perfused cat adrenal gland treated with ouabain. Biochem. Pharmacol., 29: 2669-2673.

Garcia, A. G., Garcia-Lopez, E., Horga, J. F., Kirpekar, S. M., Montiel, C., and SanchezGARCIA, P. (1981a) Potentiation of K-evoked catecholamine release in the cat adrenal gland treated with ouabain. Br. J. Pharmacol., 74: 673-680.

Garcia, A. G., Garcia-Lopez, E., Montiel, C., Nicolas, G. P., and Sanchez-Garcia, P. (1981b) Correlation between catecholamine release and sodium pump inhibition in the perfused adrenal gland of the cat. Br. J. Pharmacol., 74: 665-672.

Garcia, A. G., Hernandez, M., Horga, J. F., and Sanchez-Garcia, P. (1980) On the release of catecholamines and dopamine- $\beta$-hydroxylase evoked by ouabain in the perfused cat adrenal gland. Br. J. Pharmacol., 68: 571-583.

Holz, R. W. and SEnter, R. A. (1981) Choline stimulates nicotinic receptors on adrenal medullary chromaffin cells to induce catecholamine secretion. Science, 214: 466-468.

Nishimura, S., Sorimachi, M., and Yamagami, K. (1981) Exocytotic secretion of catecholamines from the cat adrenal medulla by sodium deprivation: Involvement of calcium influx mechanism. Br. J. Pharmacol., 72 : 305-317.

Rink, T. J. (1977) The influence of sodium on calcium movements and catecholamine release in thin slices of bovine adrenal medulla. J. Physiol. (Lond.), 226: 297-325.

SORIMACHI, M. (1968) Effects of alkali metal and other monovalent ions on the adrenomedullary secretion. Eur. J. Pharmacol., 3: 235-241.

SorimaCHI, M. and Nishimura, S. (1982) Mechanism of choline-induced secretion of catecholamines from the cat adrenal medulla: Involvement of nicotinic receptor. Jpn. J. Physiol., 32: $541-551$.

Sorimachi, M., Nishimura, S., and Yamagami, K. (1981) Possible occurrence on Na-dependent $\mathrm{Ca}$ influx mechanism in isolated bovine chromaffin cells. Brain Res., 208: 442-446.

SorimaCHI, M. and YamaGami, K. (1983) Partial metabolic inhibition stimulates adrenal medullary secretion possibly by activating $\mathrm{Na}$-dependent $\mathrm{Ca}$ influx mechanism. Brain Res., 258 : $156-158$. 